\title{
Prevalence and clinical characteristics of antibiotics associated drug induced liver injury
}

\author{
Jin Hwa Park ${ }^{1 \#}$, Susie Hong ${ }^{2 \#}$, Dae Won Jun²^, Jai Hoon Yoon ${ }^{2}$, Kang Nyeong Lee ${ }^{2}$, Hang Lak Lee ${ }^{2}$, \\ Oh Young Lee ${ }^{2}$, Byung Chul Yoon ${ }^{2}$, Ho Soon Choi ${ }^{2}$
}

${ }^{1}$ Department of Internal Medicine, Seoul Asan Hospital, Seoul, South Korea; ${ }^{2}$ Department of Internal Medicine, Hanyang University School of Medicine, Seoul, South Korea

Contributions: (I) Conception and design: DW Jun; (II) Administrative support: OY Lee, BC Yoon, HS Choi; (III) Provision of study materials or patients: DW Jun, JH Park; (IV) Collection and assembly of data: JH Park, S Hong; (V) Data analysis and interpretation: JH Park, S Hong, JH Yoon, KN Lee, HL Lee; (VI) Manuscript writing: All authors; (VII) Final approval of manuscript: All authors.

\#These authors contributed equally to this work.

Correspondence to: Dae Won Jun. Department of Internal Medicine, Hanyang University College of Medicine, 222 Wangsimni-ro, Seongdong-gu, Seoul, 133-791, South Korea. Email: noshin@hanyang.ac.kr.

Background: The use of antibiotics increases recently. Accordingly, the incidence of antibiotics associated with drug induced liver injury (DILI) also increases. The purpose of this study is to evaluate the proportion and the clinical characteristics of antibiotic associated with DILI.

Methods: This study is a retrospective study of analyzed adult patients who were referred to the department of hepatology for the elevation of liver function tests and the frequency of elevated liver enzyme of patients with prescribed antibiotics during the same period at outpatient setting as a validation set.

Results: Antibiotics associated with DILI (64.0\%) are the most common reason agent among consulting to hepatology department. Rheumatoid arthritis related drugs (11.0\%), health supplements $(5.0 \%)$, herbal medicines (4.0\%), anti-viral drugs, anti-inflammatory analgesics/acetaminophen and lipid-lowering agents $(3.0 \%)$ were next common causative drug for DILI in inpatients setting (training set). The frequency of antibiotics associated with DILI was high in order of flomoxef, cetrazole, ceftriaxone, vancomycin, piperacillin/tazobactam and amoxicillin/clavulanate. In the same period, 32\% of the patients who prescribed flomoxef showed elevated liver enzyme levels above the upper normal limit. The prevalence of flomoxef induced DILI ( $>3$ folds of ALT) was 13\% and liver enzyme levels were five times higher than upper normal limits in $5 \%$ of flomoxef groups. Hypertension or diabetes was the risk factor of flomoxef associated with DILI.

Conclusions: The Prevalence of antibiotics associated with DILI was 2-14\%. Co-morbidity with diabetes and hypertension was the risk factor of flomoxef associated with DILI.

Keywords: Chemical and drug induced liver injury; anti-bacterial agents; liver

Submitted Jul 05, 2020. Accepted for publication Jan 25, 2021.

doi: 10.21037/atm-20-5144

View this article at: http://dx.doi.org/10.21037/atm-20-5144

^ORCID: 0000-0002-2875-6139 


\section{Introduction}

Liver is an important body organ for drug metabolism. Physicians meet DILI frequently in routine practice $(1,2)$. It is reported that the incidence of DILI is approximately $1 / 10,000-1 / 100,000$ person/year (3) and it varies according with countries and institutes where the study was conducted. Table 1 shows the baseline characteristics of patients with elevated liver enzyme. It was reported that the incidences of DILI in Iceland and in France are 19.1/100,000 person/year and 13.9/100,000 person/year, respectively (4). However, the incidence of drug induced liver injury in Korea is 12/100,000 person/year (5). According to the studies on common causative agents, acetaminophen was suspected as the most common cause of DILI. Trogiltazone, valproate and halothane seem to be the next common causative drug for DILI (6).

The incidence and causative drug of DILI varies with regions. Acetaminophen, antibiotics, anticancer drugs, anesthetics and anti-tuberculosis drugs were reported to the most common causative agents that may induce liver injuries in the Western countries $(7,8)$. However, herbal medicines or prescribed traditional medicines were found to be the major cause of liver injuries in the Eastern countries $(9,10)$. Recently, as the prescription rate of antibiotics increased. The prevalence of antibiotics associated DILI also increased. Among the antibiotics associated DILI, amoxicillin/clavulanate are seemed to be the most common causative agents of DILI (11-13). Amoxicillin/Clavulanate are the most frequently-used antibiotics and the ratio of DILI according to the total number of prescribed antibiotics is still unknown. Additionally, there are many studies regarding the liver injuries caused by the herbal medicine and traditional remedies in the East, including Korea. However, there are only a few studies on the antibiotics-induced liver injuries $(5,14)$. It was difficult to exclude patients with a baseline high liver enzyme level because there was no evaluation of the baseline level of the patients. Also, depending on the frequency of prescription, a bias may occur in the evaluation of the drug-induced liver injury and the clinical aspect. This study attempted to supplement the shortcomings of previous studies by identifying the baseline liver enzyme of patients. In addition, we reviewed all patients who had been prescribed the same drug for one year to determine whether it was a common cause of increased hepatitis levels even when the frequency of prescription was adjusted.

The study herein examined the incidences of DILI caused by antibiotics and their clinical characteristics. We present the following article in accordance with the STROBE reporting checklist (available at http://dx.doi. org/10.21037/atm-20-5144).

\section{Methods}

\section{Study design}

This study is a cross-sectional study and consisted of inpatients as training set and outpatients as validation set. The study is a retrospective cross-sectional study conducted with electronic records of Hanyang University Medical Center from April 1 ${ }^{\text {st }}, 2017$ to March 31 ${ }^{\text {st }}, 2018$. All inpatients cohort were consulted to the hepatology department due to elevated liver enzyme level from April $1^{\text {st }}, 2017$ to March $31^{\text {st }}, 2018$ (one year) at single tertiary hospital. Outpatient cohort was patients who were prescribed antibiotics in outpatient clinic at the same period. The study was conducted in accordance with the Declaration of Helsinki (as revised in 2013). The study was approved by the institutional review board of Hanyang University (HYUH 2018-11-028-001) and individual consent for this retrospective analysis was waived.

\section{Inpatient population (training set)}

The study was carried through patients hospitalized at Hanyang University Seoul Hospital consulted to the hepatology department due to elevated liver enzyme from April $1^{\text {st }} 2017$ to March $31^{\text {st }}$ 2018. The selected patients are 18 or more years old and the liver enzyme level of $120 \mathrm{mg} / \mathrm{dL}$ or higher. $120 \mathrm{mg} / \mathrm{dL}$ is 3 times of the upper normal limit, $40 \mathrm{mg} / \mathrm{dL}$. However, excluded are patients whose liver enzyme level of $40 \mathrm{mg} / \mathrm{dL}$ or higher prior to administration of antibiotics $(15,16)$. The liver enzyme level of patients was regularly checked for every 2-3 days from the point the level elevated after administration of antibiotics to the point of level normalized after stop administration of antibiotics. We investigated the underlying patients prior to hospitalization about underlying diseases, sex, age, body mass index, name of a disease upon hospitalization, hospitalized department, antibiotics currently administering, and the duration of their administration.

\section{Outpatient population (validation set)}

The study limits the outpatients who were prescribed with 
Table 1 Baseline characteristics of patients with elevated liver enzyme

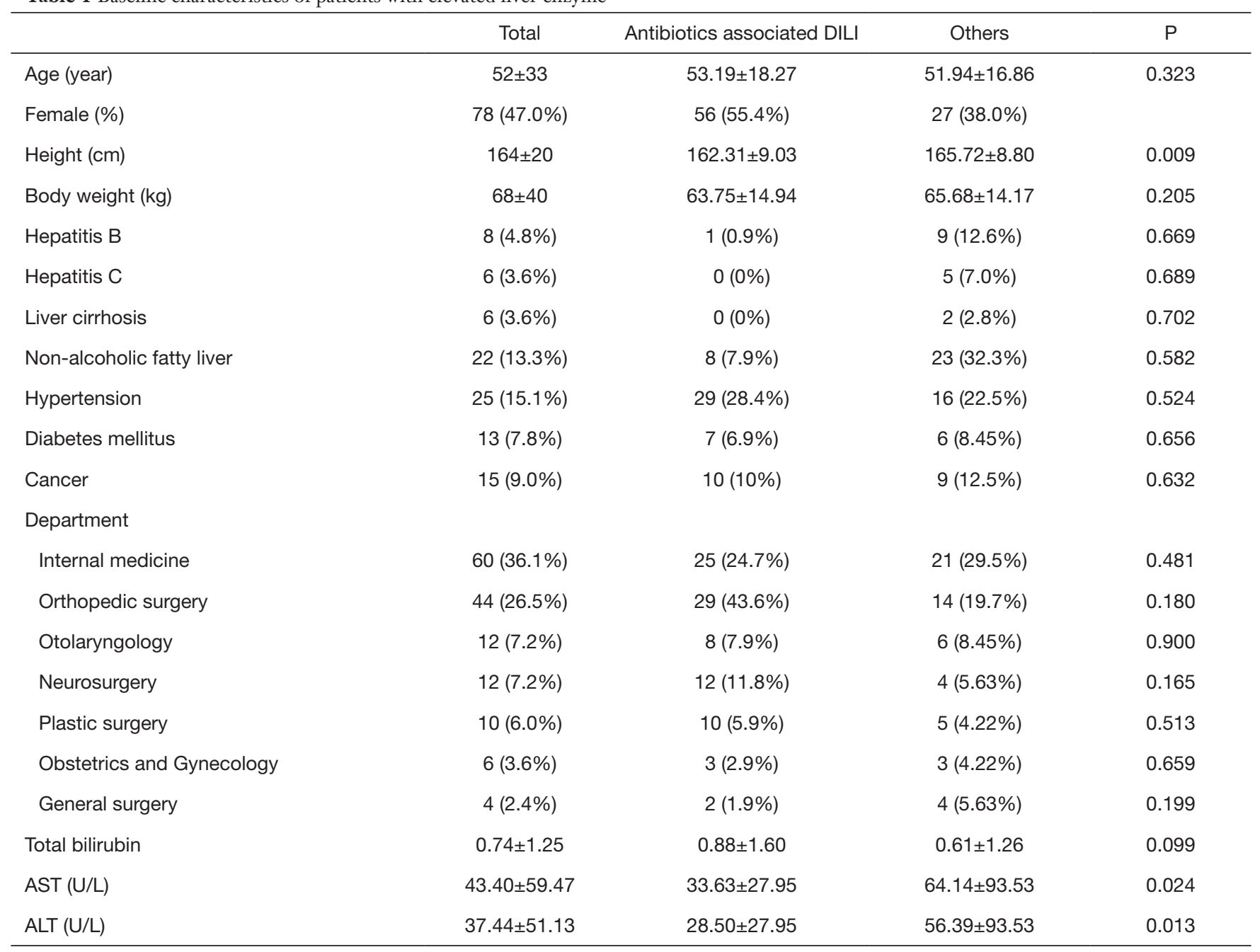

AST, aspartate aminotransferase; ALT, alanine aminotransferase.

antibiotics for more than a day from April 1 $1^{\text {st }}, 2017$ to March $31^{\text {st }}, 2018$. The patients chosen in this study are 18 or more years old and the liver enzyme level of $120 \mathrm{mg} / \mathrm{dL}$ or higher after administration of antibiotics. However, excluded are patients whose liver enzyme level of $40 \mathrm{mg} / \mathrm{dL}$ or higher prior to administration of antibiotics. The liver enzyme level of patients was measured using serum test for 14 days after the administration of antibiotics when the patients visited the outpatients' clinic. However, it failed to track the elevated level being normalized. We investigated the underlying patients about underlying disease, sex, age, body mass index, name of diseases upon outpatient visit, outpatient department, antibiotics currently taking and the duration of their administration.

\section{Definition}

DILI is defined as the case when the liver enzyme level increased 3 times of the upper normal limit $(40 \mathrm{mg} / \mathrm{dL}$ ) after drugs were administered for patients with no other causes that may increase the level (alcohol, virus, ischemia, autoimmune hepatitis and etc.). Hepatitis B patients are referred to those diagnosed with HBsAg-positive or taking medicines for Hepatitis B. Hepatitis C patients are referred to those diagnosed with HCV RNA-positive or taking medicines for Hepatitis C. NAFLD patients are defined as those with hepatic steatosis observed in the liver image or histology without secondary causes such as alcohol consumption (less than $210 \mathrm{~g} /$ week for male patients and $140 \mathrm{~g} /$ week for female patients) and medication. 


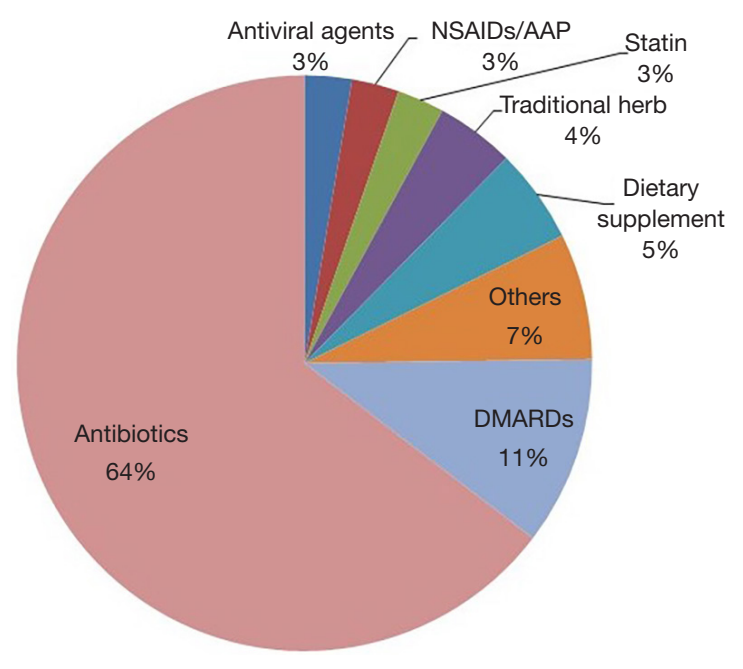

Figure 1 Drugs that cause drug induced liver injury. The causes of drug-induced liver injury were antibiotics, DMARDs, dietary supplement, traditional herb, statin, NSAIDs/AAP and antiviral agent. DMARDs, disease-modifying antirheumatic drugs; NSADIs/AAP, nonsteroidal anti-inflammatory drugs/ acetaminophen.

\section{Follow up and monitoring}

Potential causes of the elevated liver enzyme level such as the viral hepatitis or the autoimmune hepatitis were checked among all patients. When they were ruled out, drug-induced causes, such as medication, herbs and traditional remedies were evaluated. The medical history, family history, alcohol history, x-ray, ECG, complete blood count, electrolyte, liver function test, viral marker and department of interdisciplinary treatment for all patients were examined. The abdominal ultrasonography was performed, if needed. The causes of liver injury were evaluated through the classification of drugs, alcohol, virus and underlying diseases. The drugs were sub-divided into antibiotics, anti-viral drugs, DMARDs, NSAIDs/AAP, Statin, herbs, dietary supplement and others for evaluation. In the case of antibiotics associated DILI, this study looked into the department that prescribed antibiotics and reasons for such prescription were.

\section{Statistical analysis}

The data processing was carried using Microsoft Office Excel 2010 (Microsoft, Redmond, WA) and IBM SPSS Statistics. Data were expressed in median values and Fisher exact testing was used to compare groups with dichotomous variables. For continuous variables, ANOVA was applied. All $\mathrm{P}$ values are reported as 2-tailed and the level of significance was defined as 0.05 .

\section{Results}

\section{Baseline characteristics and type of DILI of inpatients (training set)}

This study analyzed 166 patients in total requested for treatment at the gastroenterology department owing to the elevated liver enzyme level as their chief complaint during hospitalization were analyzed. The mean age of patients was 52. Among them, 78 patients were female (47.0\%) The detailed description of the invested patients is shown in Table 1. The most common causative agents were antibiotics $(64.0 \%)$ followed by disease-modifying antirheumatic drugs (11.0\%), health supplement food (5.0\%), herbal medicine $(4.0 \%)$, antiviral agents, nonsteroid anti-inflammatory analgesic drugs, acetaminophen and cholesterol lowering agent (3.0\%) as shown in Figure 1. The department of internal medicine is the majority of consultation (60 patients, $36.1 \%$ ), followed by the department of orthopedics, otolaryngology, neurosurgery and plastic surgery. 113 patients (68.1\%) out of 166 patients showed the elevated liver enzyme level caused by drugs, which is the highest incidence.

\section{Antibiotics associated with DILI in inpatients (training set)}

The maximum levels of AST and ALT are 181.5U/L and 201.0 U/L respectively. After medication stop, all DILI patients naturally recovered and there were no cases of liver transplantation or death. Table 2 shows the instances and degrees of liver enzyme elevation. Antibiotics that elevated the level of liver enzyme are in the order of flomoxef, cetrazole, ceftriaxone, vancomycin, piperacillin/ tazobactam and amoxicillin/clavulanate. Flomoxef was most common antibiotics that caused DILI. Eight patients out of 24 patients in the flomoxef group showed that the liver enzymes were elevated more than three times and the liver enzyme increased 5 times or more of the upper normal limit in 3 out of 24 patients (12.5\%). The detailed degree increases in liver enzymes by antibiotics are shown in Table 3. After the administration stop of medicine, all patients were naturally recovered and it took 25 days in average to the level to be normalized. 
Table 2 The incidences and degrees of liver elevation and the degree of liver elevation

\begin{tabular}{|c|c|c|c|c|c|c|c|}
\hline & $n(\%)(n=166)$ & \multicolumn{2}{|c|}{ Total bilirubin (mg/dL) } & \multicolumn{2}{|c|}{ AST (IU/L) } & \multicolumn{2}{|c|}{ ALT (IU/L) } \\
\hline Toxic & $113(68.1 \%)$ & $0.6 \pm 0.79$ & 1.07 & $33.4 \pm 27.7$ & 181.58 & $29.9 \pm 35.6$ & 201.02 \\
\hline Antibiotics & $73(44.0 \%)$ & $0.7 \pm 0.22$ & 1.23 & $29.35 \pm 11.8$ & 138.93 & $29.0 \pm 34.1$ & 131.31 \\
\hline Antiviral agents & $3(1.8 \%)$ & $1.27 \pm 0.79$ & 0.78 & $24 \pm 6$ & 31.67 & $16 \pm 0$ & 45.33 \\
\hline NSAIDs/AAP & $3(1.8 \%)$ & $0.55 \pm 0.26$ & 0.36 & $26.5 \pm 0.5$ & 123.67 & $29.0 \pm 34$ & 104.33 \\
\hline Statin & $3(1.8 \%)$ & $0.33 \pm 0.15$ & 0.49 & $17 \pm 1$ & 136 & $14 \pm 1$ & 224 \\
\hline Traditional herb & $5(3.0 \%)$ & $0.57 \pm 0.11$ & 0.67 & $44 \pm 19.1$ & 134.4 & $33.3 \pm 18.9$ & 197.6 \\
\hline Dietary supplement & $6(3.6 \%)$ & $0.47 \pm 0.01$ & 0.49 & $24 \pm 2$ & 201.5 & $25.5 \pm 12.5$ & 379 \\
\hline Underlying disease & $40(24.1 \%)$ & $1.29 \pm 3.66$ & 1.52 & $86.3 \pm 148.4$ & 305.74 & $72.9 \pm 94.7$ & 196.5 \\
\hline Hepatitis B & $1(0.6 \%)$ & $1.03 \pm 0$ & 1.85 & $51 \pm 0$ & 59 & $51 \pm 0$ & 82 \\
\hline Hepatitis C & $1(0.6 \%)$ & $0.48 \pm 0$ & 0.60 & $28 \pm 0$ & 22 & $35 \pm 0$ & 22 \\
\hline Liver cirrhosis & $2(1.2 \%)$ & $0.48 \pm 0$ & 1.12 & $47.5 \pm 24.7$ & 58.5 & $47.4 \pm 3.84$ & 29.5 \\
\hline NAFLD & $12(7.2 \%)$ & $0.48 \pm 0.02$ & 0.73 & $40.2 \pm 25.6$ & 78.8 & $52.83 \pm 48.2$ & 115.8 \\
\hline Biliary & $2(1.2 \%)$ & $1.25 \pm 0.68$ & 1.73 & $137.5 \pm 115$ & 500 & $73.5 \pm 54.5$ & 485.5 \\
\hline Trauma & $8(4.8 \%)$ & $0.44 \pm 0.17$ & 0.60 & $30.3 \pm 5.69$ & 110.33 & $30.3 \pm 9.07$ & 65.5 \\
\hline Cancer & $5(3.0 \%)$ & $7.25 \pm 11.25$ & 3.76 & $280.67 \pm 262$ & 302 & $33 \pm 160.7$ & 296.25 \\
\hline
\end{tabular}

DMARDs, disease-modifying antirheumatic drugs; NSAIDs, nonsteroidal anti-inflammatory drugs; AAP, acetaminophen; NAFLD, nonalcoholic fatty liver disease.

\section{Antibiotics associated with DILI in outpatients}

The antibiotics prescribed for outpatients in the same period were checked and the elevated level for each drug was reviewed. Flomoxef was one of the most common antibiotics prescribed for outpatients in the same period, followed by ceftriaxone, ciprofloxacin, sulfamethoxazole/ trimethoprim, isoniazid and amoxicillin/clavulanate. Table 4 shows the frequencies of antibiotics prescription for outpatients over a specified period. The prevalence of abnormal liver enzyme was the highest in the flomoxef group. $32 \%$ of the patients prescribed with flomoxef showed elevated level of liver enzyme that exceeded the upper normal limit. 13\% of flomoxef group elevated liver enzyme more than 3 times and the prevalence of flomoxef associated with DILI was 3\% ( $>5$ times or more of the upper normal limit). Next, 14\% of the patients prescribed with ciprofloxacin had the level increased 3 times or more of the upper normal limit and $4 \%$ had the level increased 5 times or more of the upper normal limit. Figure 2 shows the frequencies and degrees of liver enzyme elevation by antibiotics for flomoxef, ciprofloxacin, isoniazid, ceftriaxone, sulfamethoxazole/ trimethoprim and amoxicillin/clavulanate.

\section{Risk factor of antibiotics associated with DILI in outpatients}

The ratio of male patients was slightly higher (male 56\% 
Table 3 The degrees of increase in liver enzymes by antibiotics

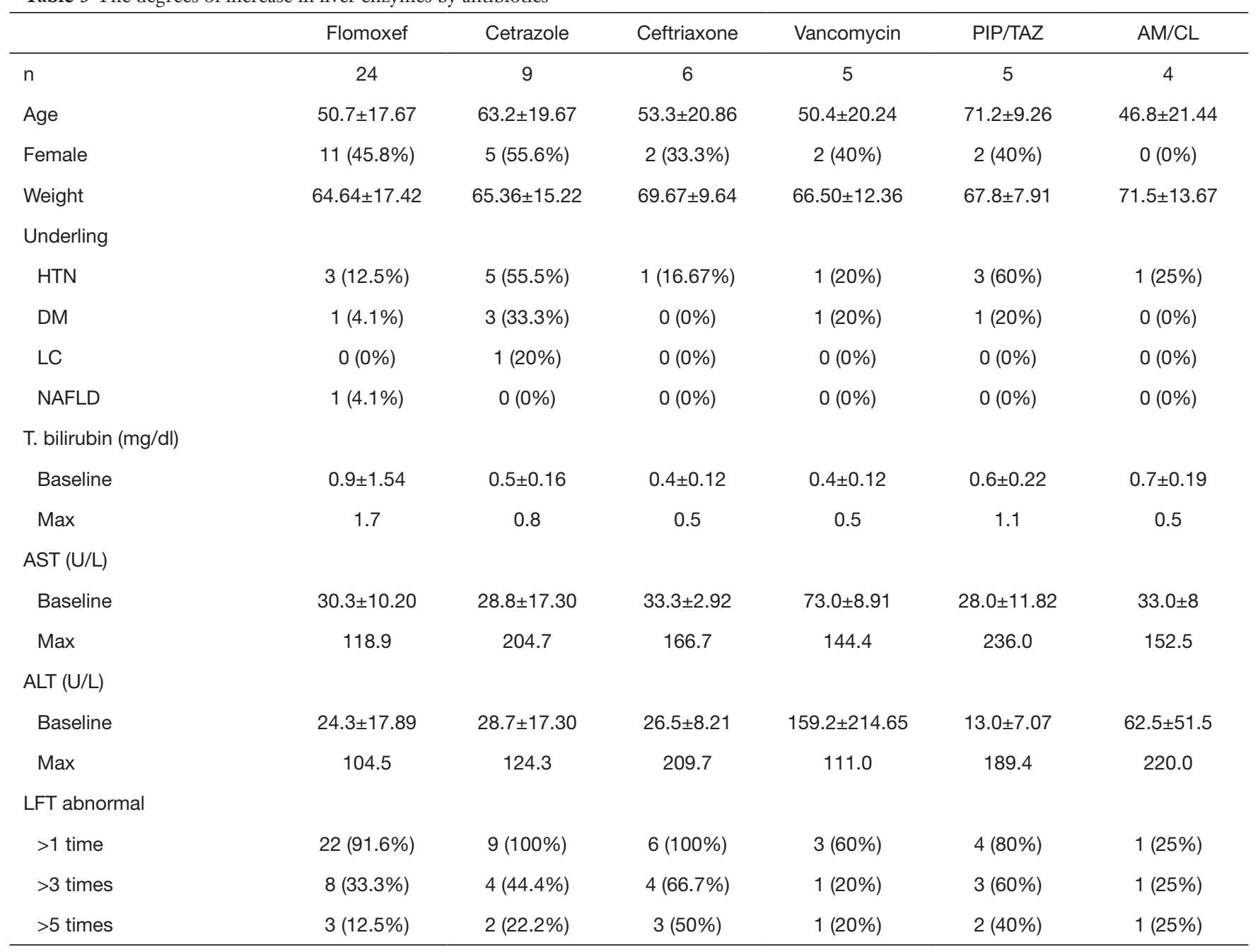

PIP/TAZ, piperacillin-tazobactam; AM/CL, amoxicillin-clavulanate; HTN, hypertension; DM, diabetes mellitus; LC, liver cirrhosis; NAFLD, non-alcoholic fatty liver disease; T. bil, total bilirubin; AST, aspartate aminotransferase; ALT, alanine aminotransferase.

Table 4 Frequencies of antibiotics prescription for outpatients over a specified period

\begin{tabular}{|c|c|c|c|c|}
\hline & $\mathrm{N}$ & Abnormal & 3 times UNL & 5 times UNL \\
\hline Ceftriaxone & 1,503 & $420(27.9)$ & $90(6.0)$ & $19(1.3)$ \\
\hline Ciprofloxacin & 954 & $249(26.1)$ & $101(16.0)$ & $41(4.3)$ \\
\hline Sulfamethoxazole/Trimethoprim & 639 & $162(25.4)$ & $12(1.9)$ & $16(2.5)$ \\
\hline Amoxicillin/Clavulanate & 307 & $53(17.3)$ & $6(2.0)$ & $2(1.7)$ \\
\hline
\end{tabular}

UNL, upper normal limit. 
A

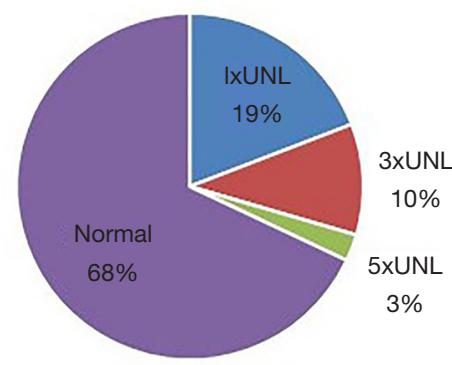

$\mathrm{D}$

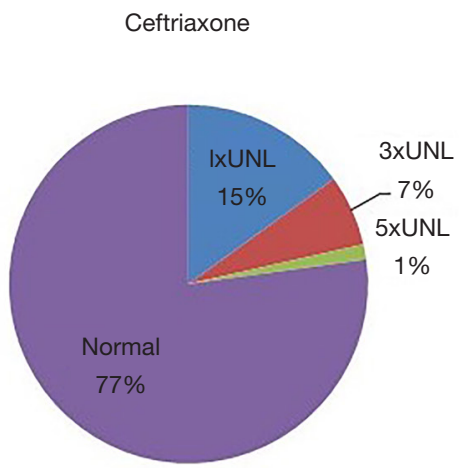

B

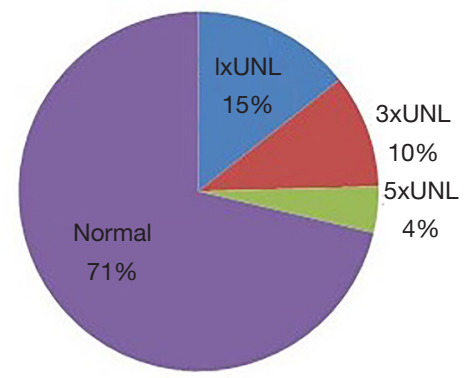

E
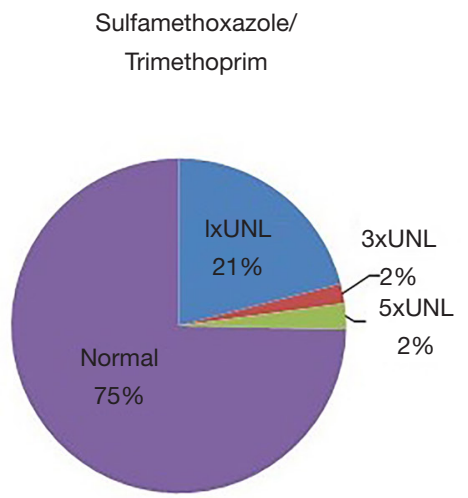

C Isoniazid

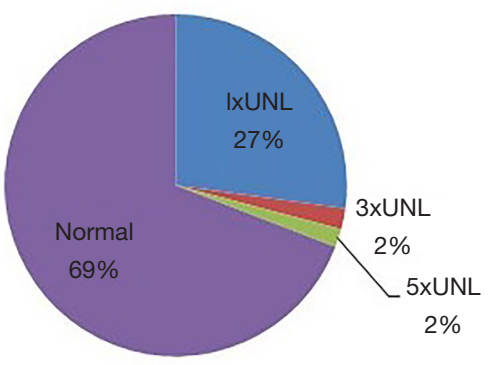

$\mathrm{F}$

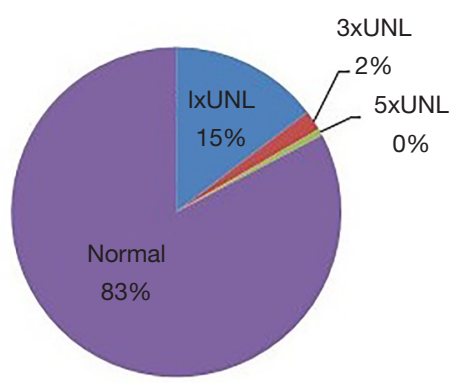

Figure 2 Frequency and degree of liver enzyme elevation by antibiotics: (A) Flomoxef, (B) Ciprofloxacin, (C) Isoniazid, (D) Ceftriaxone, (E) Sulfamethoxazole/Trimethoprim, and (F) Amoxicillin/Clavulanate.

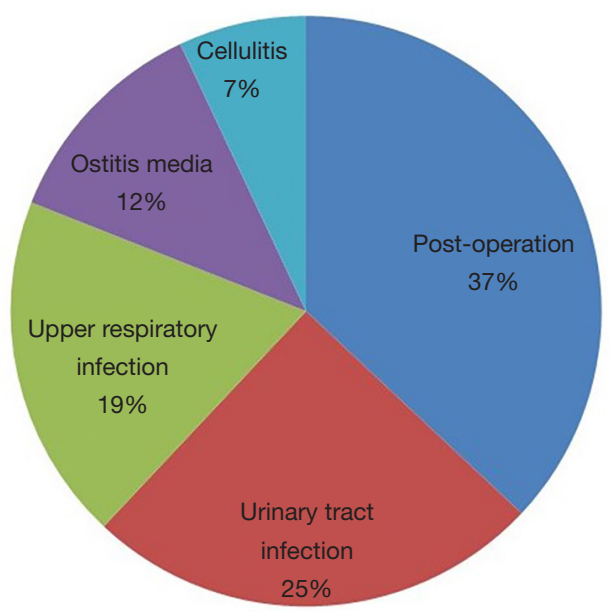

Figure 3 Purposes of prescribing patients who have been prescribed flomoxef in an outpatient setting. The main reasons for using were post-operation, urinary tract infection, upper respiratory infection. and female 44\%) than female patients. The average age was $50.5 \pm 17.2$ in flomoxef associated with DILI group. Antibiotics were mostly prescribed for preventing infection after operation among outpatients, which accounted for the largest proportion (37\%), followed by urinary tract infection (25\%), upper respiratory infection (19\%), ostitis media (12\%) and cellulitis (7\%). Figure 3 shows the purposes of prescribed patients. In addition, hypertension accounted for $14 \%$ of the underlying diseases found in outpatients with elevated liver enzyme level associated with the prescribed flomoxef, followed by diabetes (13\%), cancer (7\%) and hyperlipidemia (4\%).

\section{Discussion}

Antibiotics associated with DILI are relatively common and approximately $2-14 \%$ of outpatients may diagnose it. Our study showed that the incidence of antibiotics associated 
with DILI was $1-4 \%$. The prevalence of flomoxef and ciprofloxacin were slightly higher than other antibiotics, but the clinical significance is uncertain.

Although there have been numerous studies on liver injuries associated with prescription drugs such as antibiotics and anti-inflammatory analgesic drugs, prevalence of DILI was quite diverse according to regions, ethnics and clinical setting (4,5,17-21). Moreover, study for antibiotics associated with DILI is quite limited. Most antibiotics associated with DILI cases were based on patients who need to be newly hospitalized and there are a very few studies about the incidence of DILI upon hospitalization or outpatient treatment. According to several studies on DILI while patients were hospitalized, an antibiotic was the greatest cause of increasing the liver enzyme level just like this study result, and the incidence of DILI was the highest when administered with AmoxicillinClavulanate $(3,11)$. However, the number of subjects in the study was very small and the patients were medicated for a long time (more than 20 days in average). Thus, it has a limitation in that DILI was reported in patients whose liver injuries have already been in progress. Bjornsson et al., showed amoxicillin/clavulanate was reported to be the most common causative agent of drug-induced liver injuries. 21 out of 35,252 prescription cases, which is equivalent to $1 / 2,350$, resulted in DILI (12). Spanish DILI registry data also suggested amoxicillin-clavulanate is the most common drug related to DILI (21). Also, US DILI network's data suggested amoxicillin/clavulanate was the most common cause of idiosyncratic DILI in the DILIN registry (22) and azithromycin was the implicated agent in a higher proportion of patients with pre-existing liver disease (23). However, Latin American DILI registry showed trovofloxacin and clarithromycin was the most common causative agent (24). One Germany cross-sectional study showed the highest adjusted risk estimates for antibiotics associated DILI were calculated for clarithromycin (25). However, amoxicillin/clavulanate is one of the most frequently used antibiotics over the world, so it seemed to be needed to adjust total prescribed amount. To compensate this, our study analyzed the prevalence of several key antibiotics associated DILI using outpatients' cohort (validation set) during same period (one year). The study herein investigated the incidence of antibiotic-associated DILI based on the prescription ratio of antibiotics applied to 66,571 outpatients. The advantages of this study were that it was possible to diagnose DILI patients without symptoms and identify its causes through blood tests that were regularly conducted for inpatients and outpatients after administration of antibiotics.

Flomoxef was the most common causative drug in hospitalized patients (training set) and its prevalence was still high (abnormal liver enzyme: 13\%, and DILI: $3 \%$ respectively) in outpatient setting (validation set) after adjusting total prescribed patients. This is higher than the incidence reported in the clinical study for registration. According to flomoxef registration data, it is known that flomoxef induces increase of liver enzyme level (0.1-10\%) (26). However, previously published paper in 531 patients administered with flomoxef after receiving orthopedic operation showed prevalence of 3 times or more elevated liver enzyme level after flomoxef administration was observed in $14.3 \%$ (27). This is similar to the result of our study. Our study herein reported that the liver enzyme level increased 3 times or more in about $13 \%$. The risk factor of flomoxef associated with DILI is unclear, but there were more male patients in the study and patients with a higher baseline level showed far more increased liver enzyme level when flomoxef was started (27). The other reason of high prevalence of injury may be caused by the actual clinical sites where patients are much older and accompany other diseases. It was reported that artery and venous dilatators among drugs for hypertension may increase the liver enzyme level, and there are case reports suggesting liver injuries induced by calcium channel blockers (CCBs), angiotensin-converting enzyme (ACE) inhibitors, angiotensin receptor blockers (ARBs) and beta-blockers (8). In addition, age, genetic factors, alcohol consumption and underlying diseases were known to induce liver injuries (28). The study herein was conducted with patients receiving treatment from the tertiary hospital and it is believed that the incidence of DILI when associated with flomoxef and ciprofloxacin was higher than that specified in the pharmacopoeia because there were many elderly patients with underlying diseases prescribed with such drugs. In most cases of increased liver value due to flomoxef, it was used before and after surgery. During surgery, it was often used in combination with an antibiotic as well as an analgesic, so the increase in liver level may have been higher. Also, the liver value may have risen due to damage to muscles or bones. It was confirmed that even $13 \%$, whose liver levels increased more than 3 times, recovered without special management after stopping the drug. If the level rises through serologic follow-up observation, it should be stopped. If the patients have underlying liver disease, be careful when using it, and use it while performing repeated 
blood tests.

There are some limitations to this study. First of all, there may be bias on causes of the elevated liver enzyme level based on the prescription ratio within the hospital because the study was conducted in a single center. Unlike other studies, DMARDs account for a higher proportion to the increased level of liver inflammation. This may be resulting from the fact that there were many patients suffering from autoimmune diseases. However, when analyzing the most common causative agents, that is antibiotics, such bias may be minimized by checking the liver enzyme level of both inpatients and outpatients prescribed with the same drugs for a year. Second, study subjects included only the patients who got a consultation for elevating liver enzyme in the department of hepatology. Thus, it is limited when it comes to the study on all patients reported with the elevated level. Yet, the study limit may be reduced to a certain extent as in most cases, it is likely that most patients were enrolled in the system for interdisciplinary treatment, and the elevated liver enzyme level was examined based on the number of prescriptions associated with antibiotics. Third, since this study was conducted in people with elevated levels of hepatitis, it was difficult to evaluate in detail the frequency and clinical features of kidney injury, which plays an important role in drug metabolism. Although limited, the subjects of this study were checked for kidney injury and the frequency was confirmed to be $10.2 \%$. The drugs that affected were in the order of non-steroidal anti-inflammatory drugs, cefamezine, and piperacillin/ tazobactam and all patients improved without any special treatment after drug discontinuation. The results were similar to those of previous studies with a frequency of 10-20\% (29), but there are limitations to the results of analyzing only patients with elevated hepatitis levels.

In conclusion, the Prevalence of antibiotics associated with DILI was 2-14\%. Co-morbidity with diabetes and hypertension was the risk factor of flomoxef associated with DILI.

\section{Acknowledgments}

Funding: This work was supported by grants from the Ministry of Food and Drug Safety in 2020 (20183MFDS525). The funding source had no role in study design, implementation, data collection, analysis, and interpretation, or in the preparation, review, or approval of the manuscript.

\section{Footnotes}

Reporting Checklist: The authors have completed the STROBE reporting checklist. Available at http://dx.doi. org/10.21037/atm-20-5144

Data Sharing Statement: Available at http://dx.doi. org/10.21037/atm-20-5144

Conflicts of Interest: All authors have completed the ICMJE uniform disclosure form (available at http:// dx.doi.org/10.21037/atm-20-5144). Dr. DWJ reports grants from Ministry of Food and Drug Safety in 2020 (20183MFDS525), outside the submitted work. The other authors have no conflicts of interest to declare.

Ethical Statement: The authors are accountable for all aspects of the work in ensuring that questions related to the accuracy or integrity of any part of the work are appropriately investigated and resolved. The study was conducted in accordance with the Declaration of Helsinki (as revised in 2013). The study was approved by the institutional review board of Hanyang University (HYUH 2018-11-028-001) and individual consent for this retrospective analysis was waived.

Open Access Statement: This is an Open Access article distributed in accordance with the Creative Commons Attribution-NonCommercial-NoDerivs 4.0 International License (CC BY-NC-ND 4.0), which permits the noncommercial replication and distribution of the article with the strict proviso that no changes or edits are made and the original work is properly cited (including links to both the formal publication through the relevant DOI and the license). See: https://creativecommons.org/licenses/by-nc$\mathrm{nd} / 4.0 /$.

\section{References}

1. Lee WM. Drug-induced acute liver failure. Clin Liver Dis 2013;17:575-86, viii.

2. Larrey D, Pageaux GP. Drug-induced acute liver failure. Eur J Gastroenterol Hepatol 2005;17:141-3.

3. Vega M, Verma M, Beswick D, et al. The Incidence of Drug- and Herbal and Dietary Supplement-Induced Liver Injury: Preliminary Findings from GastroenterologistBased Surveillance in the Population of the State of Delaware. Drug Saf 2017;40:783-7. 
4. Sgro C, Clinard F, Ouazir K, et al. Incidence of druginduced hepatic injuries: a French population-based study. Hepatology 2002;36:451-5.

5. Suk KT, Kim DJ, Kim CH, et al. A prospective nationwide study of drug-induced liver injury in Korea. Am J Gastroenterol 2012;107:1380-7.

6. Bjornsson E, Olsson R. Suspected drug-induced liver fatalities reported to the WHO database. Dig Liver Dis 2006;38:33-8.

7. David S, Hamilton JP. Drug-induced Liver Injury. US Gastroenterol Hepatol Rev 2010;6:73-80.

8. Chalasani N, Fontana RJ, Bonkovsky HL, et al. Causes, clinical features, and outcomes from a prospective study of drug-induced liver injury in the United States. Gastroenterology 2008;135:1924-34, 34 e1-4.

9. Zhu Y, Niu M, Chen J, et al. Hepatobiliary and pancreatic: Comparison between Chinese herbal medicine and Western medicine-induced liver injury of 1985 patients. J Gastroenterol Hepatol 2016;31:1476-82.

10. Zhou Y, Yang L, Liao Z, et al. Epidemiology of druginduced liver injury in China: a systematic analysis of the Chinese literature including 21,789 patients. Eur J Gastroenterol Hepatol 2013;25:825-9.

11. Teschke R, Andrade RJ. Drug-induced liver injury: expanding our knowledge by enlarging population analysis with prospective and scoring causality assessment. Gastroenterology 2015;148:1271-3.

12. Bjornsson ES, Bergmann OM, Bjornsson HK, et al. Incidence, presentation, and outcomes in patients with druginduced liver injury in the general population of Iceland. Gastroenterology 2013;144:1419-25, 25 e1-3; quiz e19-20.

13. Meier Y, Cavallaro M, Roos M, et al. Incidence of druginduced liver injury in medical inpatients. Eur J Clin Pharmacol 2005;61:135-43.

14. Lee BM, Lee WC, Jang JY, et al. Clinical Features of Drug-induced Liver Injury According to Etiology. J Korean Med Sci 2015;30:1815-20.

15. Pratt DS, Kaplan MM. Evaluation of abnormal liverenzyme results in asymptomatic patients. $\mathrm{N}$ Engl J Med 2000;342:1266-71.

16. Siest G, Schiele F, Galteau MM, et al. Aspartate aminotransferase and alanine aminotransferase activities in plasma: statistical distributions, individual variations, and reference values. Clin Chem 1975;21:1077-87.

17. Abbara A, Chitty S, Roe JK, et al. Drug-induced liver injury from antituberculous treatment: a retrospective study from a large TB centre in the UK. BMC Infect Dis 2017;17:231.
18. Chalasani N, Bjornsson E. Risk factors for idiosyncratic drug-induced liver injury. Gastroenterology 2010;138:2246-59.

19. Bjornsson ES, Jonasson JG. Idiosyncratic drug-induced liver injury associated with bile duct loss and vanishing bile duct syndrome: Rare but has severe consequences. Hepatology 2017;65:1091-3.

20. Chen SS, Yu KK, Huang C, et al. The characteristics and clinical outcome of drug-induced liver injury in a Chinese hospital: A retrospective cohort study. Medicine (Baltimore) 2016;95:e4683.

21. Andrade RJ, Lucena MI, Fernandez MC, et al. Druginduced liver injury: an analysis of 461 incidences submitted to the Spanish registry over a 10-year period. Gastroenterology 2005;129:512-21.

22. Chalasani N, Bonkovsky HL, Fontana R, et al. Features and Outcomes of 899 Patients With Drug-Induced Liver Injury: The DILIN Prospective Study. Gastroenterology 2015;148:1340-52.e7.

23. Shahbaz O, Mahajan S, Lewis JH. Highlights of drug - and herb- induced liver injury in the literature from 2016: how best to translate new information into clinical practice? Expert Opin Drug Metab Toxicol 2017;13:935-51.

24. Bessone F, Hernandez N, Lucena MI, et al. The Latin American DILI Registry Experience: A Successful Ongoing Collaborative Strategic Initiative. Int J Mol Sci 2016;17:313.

25. Douros A, Bronder E, Andersohn F, et al. Drug-induced liver injury: results from the hospital-based Berlin Case-Control Surveillance Study. Br J Clin Pharmacol 2015;79:988-99.

26. Christ $W$. Pharmacological properties of cephalosporins. Infection 1991;19 Suppl 5:S244-52.

27. Kuroyama M, Otori K, Yokota S, et al. Effects of an oxacephem antibiotic on liver function in orthopedic surgery. Jpn J Antibiot 1999;52:517-23.

28. Qutrio Baloch Z, Raza MA, Abbas SA, et al. Ciprofloxacininduced Hepatotoxicity in a Healthy Young Adult. Cureus 2017;9:e1016.

29. Pannu N, Nadim MK. An overview of drug-induced acute kidney injury. Crit Care Med 2008;36:S216-23.

Cite this article as: Park JH, Hong S, Jun DW, Yoon JH, Lee KN, Lee HL, Lee OY, Yoon BC, Choi HS. Prevalence and clinical characteristics of antibiotics associated drug induced liver injury. Ann Transl Med 2021;9(8):642. doi: 10.21037/atm20-5144 